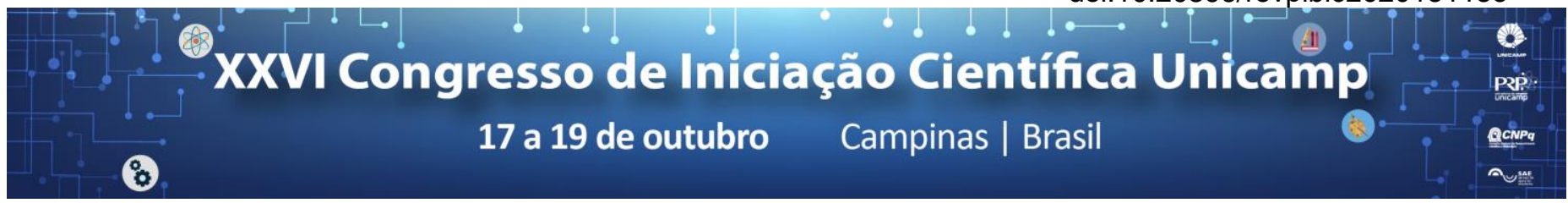

\title{
Desenvolvimento de um Manipulador UHV para o dispositivo detector de luz de um LT-STM.
}

\section{Raone Guedes Souza Cruz*, Yves Auad, Luiz Fernando Zagonel.}

\section{Resumo}

Esse projeto visou concluir o protótipo de um manipulador UHV, o manipulador foi baseado em 5 eixos, dentre eles: 3 ortogonais $\mathrm{X}, \mathrm{Y}$ e Z, movidos por transladores piezoelétricos; 1 referente à rotação na flange do tubo que suporta o manipulador; e 1 referente à inclinação no suporte dos piezos. O manipulador garantirá precisão no alinhamento óptico a fim de realizar medidas de luminescência em um microscópio de tunelamento de baixa temperatura (LT-STM). As peças que compoem o manipulador foram usinadas, devidamente limpas e montadas em bancada onde os testes iniciais de controle com os piezos foram executados.

\section{Palavras-chave:}

Manipulador UHV, Instrumentação, STM.

\section{Introdução}

Um STM é um microscópio de varredura por tunelamento que, através da corrente túnel estabelecida entre a ponta do microscópio e a amostra, torna possível medir a densidade de cargas e por fim estabelecer com precisão, tipicamente de angstrom, a topografia da amostra. Em $1988^{1}$ foi observado o fenômeno de luminescência em um STM devido a corrente túnel. Este projeto é uma continuação de um projeto de iniciação científica e visa concluir um protótipo de um manipulador UHV que será inserido dentro de um LT-STM comercial devidamente adaptado, o manipulador levará um espelho capaz de coletar a luz vinda da amostra e desta forma corroborar com o estudo de novas propriedades atômicas em semicondutores.

\section{Resultados e Discussão}

Em um primeiro momento foi feita a adaptação dos desenhos das peças para facilitar a usinagem e viabilizar conectar um sistema de resfriamento ao manipulador, após a usinagem das peças foram verificadas $\mathrm{e}$ validadas as dimensões, principalmente 0 peso pois a movimentação do manipulador é baseada no movimento de dispositivos piezoelétricos com limitação de peso (aproximadamente $1 \mathrm{~N}$ ).

Para o devido manuseio e montagem das peças foi estabelecido um protocolo de limpeza preliminar baseado na litaretura ${ }^{2}$. Após a limpeza e a adaptação de parafusos o primeiro protótipo foi montado como visto na Figura 1.

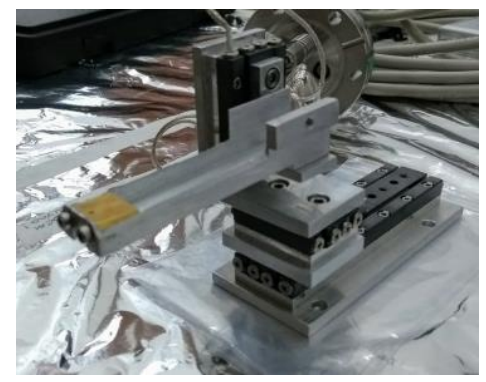

Figura 1. Protótipo do Manipulador UHV montado em bancada
Testes preliminares de controle do manipulador foram feitos, houve a calibração e configuração dos eixos, foram exploradas também as funções nativas de controle dos piezos com o software Precision Tool Comander (PTC) incluso na compra dos transladores, dentre as funções testadas destacasse a ferramenta Scan, Figura 2, capaz de, usando um parâmetros externo, realizar uma varredura bidimensional além de opções de alinhamento e de retorno ao ponto de origem, tudo de forma automática.

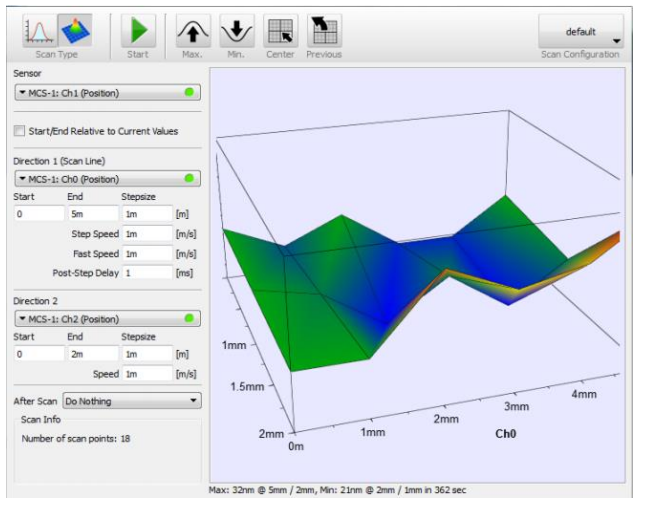

Figura 2. Varredura bidimensional $X Y$ usando como parâmetro externo a posição do manipulador $Z$.

\section{Conclusões}

O protótipo do manipulador UHV para um LT-STM foi devidamente montado e validado, as medidas conferem com o projeto em CAD, o peso está abaixo do limite dos piezos e os sistemas de controle garantem um funcionamento do manipulador a curto-prazo. Um software de controle específico deverá ser desenvolvido para garantir um controle mais específico para as medidas que serão feitas posteriormente no STM.

\section{Agradecimentos}

Agradecemos o financiamento do CNPQ e da FAPESP, projetos 2014/23399-9 e 2012/10127-5.

\footnotetext{
"Photon emission with the scanning tunnelling microscope" J. K Gimzewski, B. Reihl, J. H. Coombs, R. R. Schlittler, Z. Phys. B - Condensed Matter, vol. 72,

497, 1988.

2 "Cleaning Technical Procedure" Jason Fielden, D an Lowe, Dima Yosifov, Mark

de Jong, 2000.
} 